\title{
Parameter Estimation and Measures of Fit in A Global, General Equilibrium Model
}

\author{
Jing Liu \\ Household Credit Services \\ Channing Arndt \\ Purdue University \\ Thomas W. Hertel \\ Global Trade Analysis Project (GTAP), Purdue University
}

\begin{abstract}
Computable General Equilibrium (CGE) models have been widely used for quantitative analysis of global economic issues. However, CGE models are frequently criticized for resting on weak empirical foundations. This paper builds on recent work in macro-econometric estimation, developing an approach to parameter estimation for a widely employed global CGE model, the Global Trade Analysis Project (GTAP) model. An approximate likelihood function is developed and the set of optimum elasticity values is obtained by maximizing this approximate likelihood function in the context of a back casting exercise. In addition, two statistical tests are performed. The first of these tests compares the standard GTAP elasticity vector with the estimated trade elasticity vector. It rejects the null hypothesis of equality between the two sets of trade elasticities. The second test examines the widely maintained hypothesis known as the "rule of two", by which the elasticity of substitution across imports by sources is set equal

\footnotetext{
*Corresponding address: Jing Liu, Credit Risk Analyst Household Credit Services, 12447 SW 69th Ave Bldg B-2, Tigard OR 977224, United States of America, Tel: +1(503)686-2468, jing.x.liu@ house.com/ Channing Arndt, Associated Professor, Department of Agricultural Econoimcs, Purdue University, W.Lafayette, IN 47907, USA, Tel: +1(765)496-4304, Fax: +1(765)496-1224, E-mail: carndt@ purdue. edu, Thomas W. Hertel, Professor and Director Center for Global Trade Analysis, Purdue University, W. Lafayette, IN 47907

(C)2004-Center for International Economics, Sejong Institution, All Rights Reserved.
} 
to twice the elasticity of substitution between domestic goods and imports. We fail to reject this common rule of thumb. We conclude that there is much to be gained by nesting CGE models within an estimation framework as this opens the way for formal evaluation of model performance and parameterization.

- JEL Classification: C3, D5, F1

- Key words: CGE models, estimation, validation, trade elasticities

\section{Introduction}

Computable General Equilibrium (CGE) models have been widely used for quantitative analysis of global and regional economic issues. In the December, 2001 issue of the Journal of Economic Integration alone, there were three articles employing a multi-country CGE approach to examine trade related issues. Despite their popularity, CGE models are frequently criticized for resting on weak empirical foundations (e.g., Hansen and Heckman, 1996; Jorgenson, 1984; Singleton, 1988; Hoover, 1995; and McKitrick, 1998). The use of apparently arbitrary values for behavioral parameters and a lack of model validation are two frequently criticized aspects. For example, CGE modelers frequently assume that commodities are differentiated by origin. (This "Armington assumption" is employed in all of the papers mentioned above). Elasticities of substitution must then be specified between imports and domestic goods. These Armington elasticities of substitution have been shown to be important determinants of model results, particularly for trade related applications (Arndt, Hertel, Dimaranan, Huff, and McDougall, 1997; Roberts, 1994). Despite (or perhaps because of) the importance of these parameters, debate over appropriate values remains contentious. In addition, surprisingly little is known about the capacity of regional or global CGE models to reproduce the historical record.

This paper presents a general approach to parameter estimation and develops goodness-of-fit measures for regional and global CGE models. The method is applied to estimation of Armington substitution elasticities in a relatively standard global model focused on East Asian trade. We pose, and attempt to answer, two questions. First: what are the most sensible values for these trade elasticities, given the calibrated structure of the model and the historical record? Second: how well does the model track historical experience, particularly with respect to trade flows? To do this, the CGE model is linked to an econometric model wherein a 
stochastic error is introduced to motivate the goodness-of-fit measures. An approximate likelihood function is employed to measure the size of stochastic errors between selected predicted values from the model and the historical data. The set of optimum elasticity values is obtained by maximizing the approximate likelihood function in the context of a backcasting exercise. This approach enables us to discriminate among alternative sets of parameter values, as well as generating measures of model fit to the historical data.

\section{A. Literature Review}

\section{Brief Review of CGE Model Parameter Estimation and Calibration}

A variety of approaches have been used to obtain parameters for CGE models. By far the most common approach is to specify fairly parsimonious functional forms, obtain necessary behavioral parameters from the micro-econometric literature (or other sources), and then calibrate the remaining parameters such that the model perfectly reproduces a base year data set. This approach has the distinct advantage of not requiring time series data and leaving estimation issues to the econometricians. Nevertheless, other, more ambitious, approaches to parameter estimation and/or model validation have been attempted.

For example, direct econometric approaches to estimating the parameters of selected equations appearing in CGE models have been used (Jorgenson, 1984; Jorgenson and Slesnick, 1997; McKitrick, 1998). Typically, trade, demand, and supply parameters are estimated separately. While this approach is preferable to simple calibration based on the (invariably spotty) microeconometrics literature, Arndt, Robinson, and Tarp (forthcoming) point to a series of difficulties associated with the direct econometric approach. These include:

- substantial data demands,

- the length of run of the elasticities obtained (usually annual when CGE models typically consider longer adjustment time frames),

- the strong likelihood of structural changes during the estimation period, which is difficult to account for without a structural model, and

- failure to impose the full set of general equilibrium constraints.

Given these drawbacks, other CGE researchers have expanded the calibration method to employ two points in time. In this approach, the researcher runs the model over an historical period and compares results for some variables with the historical record. These comparisons can provide an informal basis for revising 
estimates of some important parameters. Examples of this approach include Gehlhar (1994); Kehoe, Polo, and Sancho (1995); Dixon, Parmenter, and Rimmer (1997); and Abrego and Whalley (2002). This approach has the advantage of imposing the full set of general equilibrium constraints. On the other hand, it makes limited use of the historical record and provides no statistical basis for judging the robustness of estimated parameters.

Arndt, Robinson, and Tarp (forthcoming) combine the two methods described above. They use an entropy-based metric to measure the capacity of the model to track relevant historical data over several points in time. By endogenizing key behavioral parameters, the parameter values that permit the model to best track the historical record can be estimated by minimizing the entropy distance of predicted values from historical targets. The entropy approach is motivated by information theory, which deals explicitly with cases where information is scattered, incomplete, or even inconsistent. This makes the approach attractive, particularly in the context of developing countries.

Arndt, Robinson, and Tarp point out a number of advantages of their approach. They also point out limitations. For example, while their approach permits hypothesis testing through an "entropy ratio" statistic, the statistic is known to have weak power. In addition, Arndt, Robinson, and Tarp do not consider the extensive literature that has evolved associated with parameterizing real business cycle models. This literature, and some of the potential links to CGE model calibration, is discussed in Dawkins, Srinivasan and Whalley (2000). We now turn to a review of relevant aspects of the real business cycle literature to set the stage for our subsequent econometric specification.

\section{The Real Business Cycle Literature}

Macroeconomic, dynamic, stochastic general equilibrium (DSGE) models can be viewed as a species of the genus CGE model (Hoover, 1995). Thus, it is useful to consider the empirical foundations of DSGE models in the search for ways to improve the empirical foundations of CGE models. DSGE models are well represented in the real-business-cycle literature. In the following, we review three studies in the business-cycle literature. In particular, we consider the seminal work of Kydland and Prescott as well as later works by Altug and Watson. ${ }^{1}$

\footnotetext{
${ }^{1}$ We should also mention that the works by Sims and Singleton are additional useful sources to explore the ideas of evaluating the performance of CGE models.
} 
Kydland and Prescott present a competitive equilibrium growth model of cyclical variances for a set of quarterly economic data from 1950 to 1979 for the United States. The model is a one sector, calibrated, optimal-growth model where the only driving force in the economy is exogenous technological change. Shocks to technology are assumed to follow a stochastic process with a deterministic component and a random component. The variance of the random component is set to exactly match the variance of output in the postwar US economy. Most parameters in this model are preset with a view to both microeconomic studies and steady state values for key model outputs. Remaining free parameters are determined through a grid arch over the sensible domain of parameter values so that cyclical covariances in model outputs are near those observed. No explicit metric is defined to formally judge the goodness of fit of the model (e.g., the exact definition of "near"). Altug uses maximum likelihood methods to estimate some key parameters and test the assumptions underlying a revised Kydland-Prescott model. His model establishes the linkage between the parameters of interest, the innovation to the technology shock, and the laws of motion describing the evolution of equilibrium quantities. Quarterly data on five macro variables from 1948-1985 are collected and used to construct a sample of observations on the stationary stochastic process, from which the likelihood function can be approxi-mated. The discrepancies between observed and model-predicted values are regarded as measurement errors for each series. The errors are assumed uncorrelated over time but correlated among series. Multivariate normality is implicitly assumed for the error series. The variances of the random component of technology shocks are endogenously determined in his model. Basically, his study tries to answer the following questions: What is the optimum combination of a subset of the parameter alues in the model? And, what is the magnitude of random technology shocks required such that a joint measure of the second moments of measurement errors for those five variables is minimized?

Watson suggests a new procedure for assessing the performance of the original Kydland-Prescott model. Unlike the maximum likelihood approach of Altug, Watson abandons the null hypothesis that his economic model is well specified. Rather, the model is treated as an approximation of reality where the "error represents the degree of abstraction of the model from the data" (p. 1012). With misspecification of the model assumed a priori, he resorts to devising a measure of goodness of fit for the model. This measure provides a more formalized means for judging "near" (a lacunae in the original work of Kydland and Prescott, 1982). 
Watson generates measures of fit for a DSGE with a given set of parameter values. He does not seek to estimate parameter values; however, he does point out that his proposed measure of fit could be used as a criterion for estimating parameters of interest.

While quantitative studies in the dynamic macroeconomics literature provide a rich source of ideas, there are some important differences between macroeconomic models and multi-sector CGE models. First, typical real-business-cycle models like the Kydland-Prescott model are one-good, one-agent models and have far fewer parameters than typical CGE models (Hoover, 1995). Second, the growth models in the real-business-cycle literature are based on time series while many CGE models remain fundamentally comparative static in nature. This has important implications for our paper. In the former case, information is mainly derived from time series data for evaluating model performance. In the latter case, information may be derived from multidimensional longitudinal data (e.g., a panel of results across commodities, regions, and/or time) for the same purpose. Third, many macroeconomic models are stochastic models where the driving forces of the economy contain random components and the series being tracked (such as GDP, consumption, investment) are non-stationary and co integrated. CGE models, on the other hand, are often static and deterministic. Despite these differences, we believe that it makes good sense to apply some of the ideas from the real business cycle literature to the estimation of parameters and the development of goodness of fit measures for CGE models.

\section{B. General Approach}

The method adopted by this study is similar to that employed by Altug who utilized a single likelihood index to estimate critical DSGE model parameter values. In this paper, we develop an approximate likelihood approach that focuses on discrepancies between model predictions and available data through time, across industries and across regions. Hypothesis tests can then be conducted based on the concept of the likelihood ratio. The estimation procedure is therefore established by linking the CGE model with an econometric model.

Following Arndt, Robinson, and Tarp, the structure of our CGE model may be described as a nonlinear simultaneous square system of equations:

$$
F\left(E_{t}, Z_{t}, C, \beta, \delta_{t}\right)=0 \forall t \in T
$$

where $F$ is a function generating an I-dimensional vector of real values and $t$ is the time subscript, $E_{t}$ is an I-dimensional vector of endogenous variables such as 
prices and quantities, $Z_{\mathrm{t}}$ is a vector of exogenous variables including factor endowments and policy instruments, $C$ is the vector of coefficients either computed by a calibration exercise or preset, $\beta$ is the parameter vector of interest (e.g. substitution elasticities in trade), and $\delta_{\mathrm{t}}$ is a vector of time-variant shift parameters ${ }^{2}$. CGE analysis typically proceeds by changing the vector of exogenous variables $Z_{t}$, and examining the resulting vector of endogenous variables, $E_{t}$, which satisfies the above system. If the exogenous variables, $Z_{\mathrm{t}}$, are set to match values observed in historical time periods (for factor endowments and policy instruments for example), the solution to the CGE model could be viewed as a predicted historical time path for selected variables of interest (such as trade shares).

The econometric approach proceeds by comparing the actual historic time paths for key variables with their predicted values in the following manner:

$$
Y_{t}=G_{t}\left(E_{t}, Z_{t}, C, \beta, \delta_{t}\right)+e_{t}
$$

where $Y_{t}$ is an $\mathrm{N}$ dimensional vector of historical targets, $\mathrm{G}_{\mathrm{t}}$ is a function producing the vector of model predicted values for the targets $\hat{Y}_{t}$, and $e_{t}$ is an $\mathrm{N}$ dimensional vector representing the discrepancy between historical targets and predicted values. The vector of parameters of interest, $\beta$, is endogenous and is chosen subject to the estimation criterion presented in section 4. Calibrated parameters, elements of $C$, are also endogenous with equations forcing perfect replication of the benchmark data for any economically coherent vector $\beta$. This endogenous calibration to the base year implies that $e_{t}=0$ in the base year. For years other than the base year, the elements of $\mathrm{C}$ are effectively exogenous and $\hat{Y}_{t}$ will in general differ from the observed $Y_{t}$.

The following sections provide more detail on the CGE model employed in our study as well as the underlying social accounting matrix, the historical data and the estimation approach.

\section{The CGE Model}

We employ a modified version of a standard, global CGE model developed by Rutherford (1998) and nick-named "GTAP in GAMS." As such, it is closely

\footnotetext{
${ }^{2}$ In reality, $Z_{\mathrm{t}}$ may be partitioned into two parts as $\left\{Z_{t}\right\}=\left\{Z_{t}^{o}\right\} \cup\left\{Z_{t}^{U}\right\}$ where $\left\{Z_{t}^{o}\right\}$ are observable and $\left\{Z_{t}^{U}\right\}$ are unobservable. For ease of notation, the unobserved variables $\left\{Z_{t}^{U}\right\}$ are assumed constant over time henceforth except where explicitly noted.
} 
related to many of the global CGE studies reported in earlier volumes of this journal. Modifications to the model structure focus on the Cobb-Douglas representations of preferences and technology. These are replaced with Linear Expenditure System (LES) preference structures, and Constant Elasticity of Substitution (CES) production functions. In addition, a time index is added to every variable in the model. The addition of the time subscript essentially creates a series of CGE models (one for every element of the time index) that are not linked in any way (no explicit dynamic elements). This permits the model to be simultaneously solved for a series of static equilibria--each corresponding to a different period in time.

The remaining features of this model are relatively standard. Investment, saving, and government expenditure are exogenous. Factor endowments are combined in a CES function to produce value added. Value added combines with intermediate inputs in a Leontief fashion to produce final goods. Products are differentiated by origin, and imported and domestic goods are combined in a nested CES function in the tradition of Armington (1969) to produce a composite good that is utilized domestically by firms, government and the single private household. At a lower nest, imports from different regions are aggregated to form a composite import commodity. The elasticity of substitution across sources of imports is labeled $\sigma_{M}$. In the upper level nest, composite imports and domestic production for each commodity are combined with elasticity of substitution $\sigma_{D}$.

The final demands in each region are determined by a representative regional household, which is endowed with primary factors, tax revenue, and an exogenously specified net transfer from other regions. Total income is allocated to savings, public demand and private demand. Investment is exogenous while private and public demand for commodities is determined by utility maximizing behavior represented by a Linear Expenditure System (LES) and a Cobb-Douglas utility function, respectively. International transportation inputs are proportional to trade and are defined by a CobbDouglas aggregate of international transport inputs supplied by different countries. As with many global models, goods produced for exports substitute perfectly with goods produced for domestic consumption, but imperfectly with exports from other regions (e.g., Hertel or McKibbin and Wilcoxen). 


\section{The Social Accounting Matrix and The Historical Data}

\section{A. The Social Accounting Matrix}

All variables in the model, $E_{t}$, are initially calibrated to the version 4 GTAP database (McDougall, Elbehri, and Truong, 1998). GTAP version 4 provides a fully reconciled picture of the global economy in 1995 broken into 45 sectors and 40 regions. Computational burdens prevent use of the fully disaggregated dataset. Therefore, we employ a 10-region by 10-sector aggregation strategy (shown in Table 1) that is quite similar to the aggregation strategy employed by Gehlhar (1994) in his earlier two-period calibration exercise using the GTAP model. The emphasis in the aggregation is on East Asia. These economies were among the most dynamic during the period of interest in this study. The strong shifts in trade and production structure over the estimation period should help to identify the underlying parameters of interest.

\section{B. The Historical Data}

External data series may be classified into two categories. The first category includes all exogenous variables (elements of $Z_{t}$ ), which are used to shock the model backward in time. This category includes investment, government expenditure, tariff equivalents, net capital inflow, and factor endowments in four categories $^{3}$ : agricultural land, skilled labor, unskilled labor, and capital stocks. The

Table 1. Sectors and regions in the study

\begin{tabular}{llcl}
\hline \multicolumn{1}{c}{ Sectors } & \multicolumn{1}{c}{ Regions } \\
\hline AGR & Agriculture & USC & USA and Canada \\
PAG & Processed Foods & MEX & Mexico \\
FMN & Fuels And Minerals & JPN & Japan \\
CTX & Clothing And Textiles & KOR & Korea \\
OLT & Other Light Manufacturers & TWN & Taiwan \\
CHM & Chemicals & THA & Thailand \\
MEV & Machinery-Equipment-Vehicles & IDN & Indonesia \\
BAM & Basic Manufacturers & CHN & China \\
NSV & Non-traded Services & REA & Other East Asia \\
TSV & Traded Services & ROW & Rest of World \\
\hline
\end{tabular}

\footnotetext{
${ }^{3}$ Time series data set for natural resource (the fifth factor endowment in GTAP version 4) is not available and is assumed unchanged over time.
} 
second category of data includes GDP, exports by commodity, and imports by commodity at the regional level. These data serve as historical targets $\left(Y_{t}\right)$ for the endogenous variables in the model.

As noted above, the base year for the GTAP v4 data is 1995. The years selected as historical targets are 1986, 1989, and 1992. We adopt three-year intervals in recognition of the medium-term nature of this CGE model. Land, labor, capital and national accounts data were derived from a variety of sources. Details on the sources for these time series (as well as greater detail on the data discussed below) can be found in Liu (2001). Time-series trade data were prepared by Mark Gehlhar (1998). These data record reconciled bilateral merchandise trade at FOB values. Table 2 reports the ratios of 1986 to 1995 values for these key variables. Capital inflow data were obtained from the International Monetary Fund. The protection data used in this study were obtained from UNCTAD (Coyle et al.).

There are many limitations in the time series protection data. The most severe of these limitations is the problem posed by non-tariff barriers (NTBs). The UNCTAD data provides us with a coverage ratio (CR) for NTBs and we combine this with the average tariff(TF) to obtain a composite tariff (CTF) using the following formula: $\mathrm{CTF}=\mathrm{TF} /(1-\mathrm{CR})$. Thus, at very high levels of NTB coverage, the composite tariff becomes quite high. Since we are primarily interested in the ratio of protection in two periods, it is changes in CR that will be most significant. The most dramatic changes in NTBs over this period occurred in agriculture, between 1992 and 1995. During this period, NTBs were converted to tariffs as a result of the Uruguay Round Agreement or structure. Since the objective of this

Table 2. Summary for key variables in $1986(1995=1)$

\begin{tabular}{cccccccccc}
\hline \multicolumn{9}{c}{ Exogenous Variables } \\
\hline & Land & Unskilled & Skilled & Capital & Investment & Gov. Esp. & GDP & Imports & Exports \\
\hline USC & $101 \%$ & $94 \%$ & $77 \%$ & $80 \%$ & $75 \%$ & $94 \%$ & $81 \%$ & $71 \%$ & $59 \%$ \\
MEX & $91 \%$ & $78 \%$ & $68 \%$ & $82 \%$ & $89 \%$ & $95 \%$ & $87 \%$ & $40 \%$ & $44 \%$ \\
JPN & $108 \%$ & $97 \%$ & $76 \%$ & $66 \%$ & $69 \%$ & $85 \%$ & $77 \%$ & $48 \%$ & $70 \%$ \\
KOR & $108 \%$ & $87 \%$ & $56 \%$ & $39 \%$ & $36 \%$ & $58 \%$ & $48 \%$ & $33 \%$ & $40 \%$ \\
TWN & $102 \%$ & $89 \%$ & $59 \%$ & $46 \%$ & $38 \%$ & $62 \%$ & $53 \%$ & $29 \%$ & $40 \%$ \\
THA & $98 \%$ & $85 \%$ & $71 \%$ & $41 \%$ & $26 \%$ & $68 \%$ & $43 \%$ & $19 \%$ & $26 \%$ \\
IDN & $96 \%$ & $79 \%$ & $71 \%$ & $43 \%$ & $32 \%$ & $68 \%$ & $52 \%$ & $39 \%$ & $46 \%$ \\
CHN & $101 \%$ & $87 \%$ & $80 \%$ & $43 \%$ & $43 \%$ & $65 \%$ & $42 \%$ & $23 \%$ & $17 \%$ \\
REA & $89 \%$ & $83 \%$ & $55 \%$ & $57 \%$ & $43 \%$ & $60 \%$ & $56 \%$ & $30 \%$ & $38 \%$ \\
ROW & $98 \%$ & $88 \%$ & $67 \%$ & $83 \%$ & 805 & $86 \%$ & $82 \%$ & $65 \%$ & $65 \%$ \\
\hline
\end{tabular}


Table 3. Composite tariff ratios of 1986 to 1995

\begin{tabular}{lccccccc}
\hline \multicolumn{1}{c}{ SECTOR } & USC $^{\mathrm{a}}$ & MEX & JPN & KOR/TWN & CHN & THA/IDN/REA & ROW $^{\mathrm{b}}$ \\
\hline AGR & 1.07 & 0.74 & 0.94 & 1.77 & 1.22 & 1.18 & 1.14 \\
PAG & 1.36 & 0.74 & 0.97 & 1.65 & 1.57 & 1.28 & 1.06 \\
FMN/BAM & 1.78 & 1.12 & 1.06 & 1.75 & 0.80 & 0.98 & 1.35 \\
CTX & 2.35 & 1.07 & 0.92 & 2.46 & 0.82 & 1.35 & 1.26 \\
OLT & 1.08 & 2.02 & 1.25 & 2.48 & 0.46 & 0.93 & 1.81 \\
CHM/MEV & 1.22 & 0.82 & 1.34 & 2.18 & 0.84 & 1.33 & 1.02 \\
\hline
\end{tabular}

${ }^{a}$ These tariff ratios refer to the United States

${ }^{\mathrm{b}}$ These tariff ratios refer to Western Europe

exercise was to estimate a tariff equivalent for the NTBs and then convert the NTB to a tariff equivalent, we have avoided using a formula for CTF in this case and instead we have simply assumed that agricultural protection, as measured by the composite tariff, was unchanged over this period.

A summary of the estimated composite tariff ratios (1986/1995) is reported in Table 3. Where the entry in this table is greater than one, some liberalization is presumed to have occurred. Where it is less than one protection is estimated to have increased. The most striking result in this Table is the increase in CTF for China's imports of manufacturers. This does not appear to be representative of what happened in China during this period. The discrepancy is likely due to the introduction of "duty drawbacks" in the 1990's to promote manufacturing exports (Ianchovichina and Martin, 2001). As a result, tariff collections are only a small fraction of that predicted by China's statutory tariffs. This is but one of many limitations in our protection data. Another is the absence of bilateral tariffs and hence tariff preferences. This affects Mexico, in particular, which joined NAFTA over this period. Unfortunately, global time series for effectively applied tariffs are not currently available.

\section{The Econometric Model}

\section{A. Parameters to be Estimated}

The focus of most global or regional general equilibrium models is on international trade, and values for Armington parameters are key determinants of model predictions for trade flows. Estimation thus focuses on choosing values for Armington trade elasticities that allow the model to fit historical trade patterns as closely as possible 
(based on the metric presented below). While the focus is on choosing Armington parameters that accurately predict trade shares, other unobservable parameters must also be estimated in order to generate a viable representation of the global economy. In particular, rates of technical change by activity and the tendency for trade to constitute a larger share of economic activity must be accounted for. Before presenting the estimator, these two issues are discussed.

Technological progress is relatively easy to account for. During the period of this study, economic growth (measured by GDP) in the East Asian region cannot be explained by factor accumulation or other observable sources of growth (such as policy shifts that enhance the efficiency with which existing resources are used). Technological change is viewed as the remaining source of growth. To implement this idea, Hicks-neutral technological progress variables are introduced into the model. These variables are time- and region-specific, but sector-generic. Accordingly, these variables allow the model to exactly hit the GDP targets for each region and time period.

Accounting for the growth of trade as a share of GDP is more challenging. Since World War II, international trade has grown much more rapidly than global GDP. A number of factors, such as reduced tariffs, increased quality and timeliness of transport, and improved communications, have served to spur the growth of trade. However, particularly over the estimation period, these factors cannot explain the rapid growth in trade that has been observed (see Table 2). One explanation that has been proposed is the erosion of home preference biases, which McCallum (1995) and others have found to be very large, even between the United States and Canada. Under this theory, importers have latent demand but little experience with many of the products available on international markets. Their preferences are thus biased towards home-produced goods with which they have previous experience. However, as experience with imported goods increases, these home preference biases (HPB) erode.

In this analysis, we assume that erosion of HPB accounts for the residual growth in trade that cannot be accounted for through other factors (such as changes in tariffs and transport costs). To implement this, we add a new variable, $\delta$, to the CES Armington import aggregator functions. It is indexed over time as well as for two regional groupings - the developed countries (DC) and the less developed countries (LDC). This new variable acts a shifter of the CES import aggregator functions. So, looking backward in time, for any given price ratio between aggregate imports and domestic supplies $(\delta$ enters the top nest that 
combines aggregate imports and domestic supplies), $\delta$ shifts the indifference curves such that fewer imports are demanded. The values of the elements of the vector $\delta$ are constrained such that the model predicted total trade volumes for DC and LDC hit the targets exactly.

\section{B. Econometric Specification}

We now turn our attention to the econometric model. Let $y_{t}^{(i, r)}=\left(m_{t}^{(i, r)}, x_{t}^{(i, r)}\right)$, where $m_{t}^{(i, r)}$ and $x_{t}^{(i, r)}$ are imports and exports of sector $\mathrm{i}$ at region $\mathrm{r}$ at time $\mathrm{t}$, we may view $y_{t}^{(i, r)}=\left\{y^{(i, r)}\right\}$ as stacked $N_{y} \times N_{t}$ multivariate and we have $N_{r} \times N_{i}$ observations, where: $N_{r}, N_{i}, N_{y}$ and $N_{t}$ are the number of regions, sectors, targets, and points in time, respectively. The econometric model has the form:

$$
\log \left(y_{t}^{(i, r)} / y_{95}^{(i, r)}\right)=\log \left(\hat{y}_{t}^{(i, r)} / \hat{y}_{95}^{(i, r)}\right)+\varepsilon_{t}^{y}(i, r)
$$

where, $=$ are the calibrated multivariate at the benchmark year 1995; $y_{t}^{(i, r)}$, $\hat{y}_{t}^{(i, r)}$, and $\varepsilon_{t}^{y}(i, r)$ are the empirical sampled multivariate, model predicted multivariate, and multivariate residual, respectively. Denote $\tilde{\varepsilon}=\left\{\varepsilon_{t}^{y}\right\}=\left(\varepsilon_{t}^{m}, \varepsilon_{t}^{x}\right)$ ' $=\left(\varepsilon_{92}^{m}, \varepsilon_{92}^{x}, \varepsilon_{89}^{m}, \varepsilon_{89}^{x}, \varepsilon_{86}^{x}, \varepsilon_{86}^{m}\right)^{\prime}$ as the stacked $N_{y}$ x $N_{t}$ multivariate residuals. Our estimation is carried out by assuming $\tilde{\varepsilon}$ is multivariate normal with mean vector zero and variance-covariance matrix $\Omega$. In this study, $\tilde{\varepsilon}$ has $N_{y}$ x $N_{t}=2 * 3=6$ dimension and total number of observation $\tilde{\varepsilon}(i, r)$ is $N_{i} \times N_{r}=10 * 8=80$. Since, by construction, total predicted trade volumes are equal to actual trade volumes, equation 3 has an equivalent form in terms of shares:

$$
\log \left(S_{t}^{y}(i, r) / S_{95}^{y}(i, r)\right)=\log \left(\hat{S}_{t}^{y}(i, r) / S_{95}^{y}(i, r)\right)+\varepsilon_{t}^{y}(i, r) .
$$

Equation 4 focuses on the share ratios while equation 3 focuses on the volume ratios. Therefore, $\varepsilon_{t}^{y}(i, r)=\log \left(y_{t}^{(i, r)} / \hat{y}_{t}^{(i, r)}\right)=\log \left(S_{t}^{y}(i, r) / \hat{S}_{t}^{y}(i, r)\right)$.

Our objective is to select a transformation function $\mathrm{f}$ such that $\varepsilon_{t}^{y}(i, r)=f\left(y_{t}^{(i, r)} / \hat{y}_{t}^{(i, r)}\right)$ appears as independently and identically distributed (iid) for all industries $i$ and regions $r$. Once this has been obtained, and given the variance and covariance matrix $\Omega$ of the multivariate residuals $\tilde{\varepsilon}$, the approximate likelihood function is easy to derive by following Gallant and Holly (1980) and Altug (1989). The conditional density for $\varepsilon_{t}^{y}$ given $\Omega$ has the form:

$$
\operatorname{Pr}\left(\varepsilon_{t}^{y} \mid \Omega\right)=2 \pi^{-N_{r} N_{t} / 2}(\operatorname{det} \Omega)^{-1 / 2} \exp \left[-\left(\varepsilon_{t}^{y}\right)^{\prime} \Omega^{-1} \varepsilon_{t}^{y} / 2\right]
$$


This applies, regardless of the exact linkage between the targets, the parameters of interest $\beta$, and the state parameters of HPB and technological progress: $\delta_{\mathrm{t}}=$ $\left\{\zeta_{t}^{D C}, \zeta_{t}^{L D C}, t e c h_{t}^{r}\right\}$. In this study, needs to be estimated and the concentrated loglikelihood function for parameters $\beta, \delta_{\mathrm{t}}$ and $\Omega$ can be expressed as a function of all observed $\varepsilon_{t}^{y}$ and $z_{t}$

$$
\begin{aligned}
& \log L_{E}\left\{\beta, \delta_{t}, \Omega\right\}=\sum_{(i, r)} \log \left\{\operatorname{Pr}\left(\varepsilon_{t}^{y}(i, r) \mid z_{t}, \beta, \delta_{t}, \Omega\right)\right\} \\
& =\text { Constant }-\left(N_{r} N_{i} / 2\right)^{*} \log (\operatorname{det} \Omega)-\sum_{i, r}\left\{\varepsilon_{t}^{y}(i, r)^{\prime} \Omega^{-1} \varepsilon_{t}^{y}(i, r) / 2\right\} \\
& =\text { Constant }-\left(N_{r} N_{i} / 2\right)^{*} \log (\operatorname{det} \Omega)-\operatorname{tr}\left(\Omega^{-1}\right) \sum_{i, r}\left\{\varepsilon_{t}^{y}(i, r)^{\prime} \varepsilon_{t}^{y}(i, r) / 2\right\}
\end{aligned}
$$

Here $\operatorname{det}(\Omega)$ is the determinant of $\Omega, \operatorname{tr}\left(\Omega^{-1}\right)$ the trace of matrix $\Omega^{-1}$, and is a positive scalar. The likelihood ratio test is based on the statistic

$$
\mathrm{T}=-2\left[\log L_{E}\left(\tilde{\sigma}^{k}, \tilde{\beta}_{t}^{n}, \tilde{\Omega}\right)-\log L_{E}\left(\hat{\sigma}^{k}, \hat{\beta}_{t}^{n}, \hat{\Omega}\right)\right]
$$

where the first term inside the parentheses is the restricted log-likelihood and the second term the unrestricted log-likelihood.

Our approach motivates two sets of valuable statistics. The log-likelihood ratio statistic in equation 7 can be used for hypothesis tests. In addition, the variance of the approximate errors in equations 3 and 4 can be used to construct pseudo $R^{2}$ measures for each variable of the multivariate in a manner similar to a standard regression model. The $R^{2}$ statistics may be used to compare the overall fits under alternative scenarios.

To estimate $\Omega$, we first restrict its structure in order to preserve degrees of freedom. Specifically, we adopt a "nested" correlation structure in which the correlation coefficients between import residuals $\varepsilon_{t}^{m}(i, r)$ and export residuals $\varepsilon_{t}^{x}(i, r)$ are assumed to be of the form: $\rho_{t}=\rho$. This is a sensible assumption since this correlation is largely determined by the model structure. The veracity of this assumption is also confirmed by post-estimation residual analysis. Autocorrelation is assumed to be the same for exports and imports $\rho_{t i_{-} t j}^{m}=\rho_{t i_{-} t j}^{x}$ for all time pairs $\left(t_{i}, t_{j}\right)$. Heteroscedasticity is assumed to be time-specific. This is a very reasonable assumption reflecting both the decreasing predictive power of the model and the 
reduction in data quality as one moves backward in time.

We are now in a position to re-stack the multivariate as $\tilde{\varepsilon}=\left\{\varepsilon_{t 1}, \varepsilon_{t 2}, \varepsilon_{t 3}\right\}=\left\{\left(\varepsilon_{t 1}^{m}, \varepsilon_{t 1}^{x}\right)\right.$, $\left.\left(\varepsilon_{t 2}^{m}, \varepsilon_{t 2}^{x}\right),\left(\varepsilon_{t 3}^{m}, \varepsilon_{t 3}^{x}\right)\right\}$ with pair-wise correlation $\rho_{t}=\rho \neq 1$, autocorrelation $\rho_{t i_{-} t j}^{m}=\rho_{t i_{-} t j}^{x}$ $=\rho_{t j}^{t j}$ and Heteroscedasticity $\operatorname{Var}\left(\varepsilon_{t}^{m}\right)=\operatorname{Var}\left(\varepsilon_{t}^{m}\right)=\left(A_{t}\right)^{2} \sigma^{2}$ while $A_{92}$ is normalized and fixed as unitary. In addition, $E\left(\varepsilon_{t}^{m}\right)=E\left(\varepsilon_{t}^{x}\right)=0$. These assumptions may be expressed using $\otimes$ to denote the Kronecker product as:

$$
\begin{aligned}
\Omega & =\sigma^{2}\left(A_{t}^{2} R^{t}\right) \otimes R_{M_{-} X} \\
R_{M_{-} X} & =\left(\begin{array}{ll}
1 & \rho \\
\rho & 1
\end{array}\right), R^{t}=\left[\begin{array}{ccc}
1 & p_{89}^{92} & p_{86}^{92} \\
p_{89}^{92} & 1 & p_{86}^{89} \\
p_{86}^{92} & p_{86}^{89} & 1
\end{array}\right], \text { and } A_{t}=\left[\begin{array}{ccc}
1 & 0 & 0 \\
0 & A_{89} & 0 \\
0 & 0 & A_{86}
\end{array}\right] .
\end{aligned}
$$

The three matrices above represent: the pair-wise correlation matrix between imports and exports $\left(\mathrm{R}_{\mathrm{m}_{-} \mathrm{x}}\right)$, the autocorrelation matrix $\left(\mathrm{R}^{\mathrm{t}}\right)$, and the normalized heteroscedasticity matrix $\left(A_{t}\right)$, respectively.

In this study, the relationships between the residuals and the elements of $\Omega$ are implemented as a set of constraints. The whole CGE model is also converted into a set of constraints. The approximate log-likelihood function (equation 6) is the objective function of the resulting optimization problem. The objective may be expressed as a real valued function of residuals and elements of $\Omega$, which are ultimately related to the trade elasticities.

We now turn to the estimation of elements in $\Omega=\sigma^{2}\left(A_{t}^{2} R^{t}\right) \otimes R_{M_{-} X}$. Greene (1993, p365-369) presents a lengthy discussion of this issue. Due to space constraints, we appeal here to the reader's intuition. We first establish the linkages between the elements of $\Omega$ and residuals by means of the linear transformation $\varepsilon^{\prime}=\varepsilon \cdot \Omega^{-1 / 2}$ where transformed residuals $\varepsilon^{\prime}$ are independent of each other (Greene, p362). In so doing, we can either compute or directly link the elements of with residuals. To reduce the computational burden, we use a step-by-step residual transformation approach. The heteroscedasticity across time $A_{t}$ is straightforward to estimate as:

$$
A_{t}=A_{92} \sum_{r, i}\left[\left(\varepsilon_{t}^{m}(r, i)\right)^{2}+\left(\varepsilon_{t}^{x}(r, i)\right)^{2}\right] / \sum_{r, i}\left[\left(\varepsilon_{92}^{m}(r, i)\right)^{2}+\left(\varepsilon_{92}^{x}(r, i)\right)^{2}\right] .
$$

Next, we obtain the transformed residual $\varepsilon_{t}^{1}(i, r)=\left(\varepsilon_{t}^{1 m}(i, r), \varepsilon_{t}^{1 x}(i, r)\right)=\varepsilon_{t}(i, r) / A_{t}$ which is free of heteroscedasticity. The next transformation involves correcting for 
the correlation between exports and imports:

$$
\rho=\left\{\sum_{t, r, i}\left(\frac{\varepsilon_{t}^{m}(r, i)}{A_{t}}\right)\left(\frac{\varepsilon_{t}^{x}(r, i)}{A_{t}}\right)\right\} /\left\{\sum_{i, r, i}\left(\left(\frac{\varepsilon_{t}^{m}(r, i)}{A_{t}}\right)^{2}\right)^{*}\left(\sum_{t, r, i}\left(\frac{\varepsilon_{t}^{x}(r, i)}{A_{t}}\right)^{2}\right)\right\}^{1 / 2} .
$$

Since the correlation matrix $R_{M_{-} X}$ is positive definite, $\mathrm{P}=\left(R_{M_{-} X}\right)^{-1 / 2}$ is guaranteed to exist. Transforming the heteroscedasticity-free residual $\left.\varepsilon_{t}^{1}(i, r)\right)$ by premultiplying P, we have $\varepsilon_{t}^{\prime}(i, r)=\mathrm{P} . \varepsilon_{t}^{1}(i, r)$, which is correlation-free between $\varepsilon_{t}^{\prime m}$ and $\varepsilon_{t}^{\prime}$, with expected variance $\operatorname{Var} \varepsilon_{t}^{\prime}(i, r)=\sigma^{2}$.

The same approach is applied for estimating autocorrelation $R$ '. Here, the coefficients $\rho_{t 1}^{t 2}$ are estimated as:

$$
\rho_{t 1}^{t 2}=\sum_{r, i}\left(\varepsilon_{t 1}^{\prime m}(r, i) \cdot \varepsilon_{t 2}^{\prime m}(r, i)\right)+\varepsilon_{t 1}^{\prime x}(r, i) \cdot \varepsilon_{t 2}^{\prime x}(r, i) /\left(N_{y} N_{r} N_{i} \sigma^{2}\right)
$$

Transforming $\varepsilon_{t}^{\prime}(i, r)$ results in new residual $\varepsilon_{t}^{\prime \prime}(i, r)=\left(R^{t}\right)^{-1 / 2} \varepsilon_{t}^{\prime}(i, r)$, which is free of correlation, autocorrelation, and heteroscedasticity. We have expected variance $\operatorname{Var}\left(\varepsilon_{t}^{\prime \prime}(i, r)\right)=\sigma^{2}$. In addition, $\varepsilon_{t}^{\prime \prime}(i, r)$ is distributed normally since $\varepsilon_{t}^{m}(i, r)$ and $\varepsilon_{t}^{x}(i, r)$ are by assumption normally distributed and all transformations are linear.

Finally, the following relationship between the estimated $\sigma^{2}$ and $\varepsilon_{t}^{\prime \prime}(i, r)$ may be established:

$$
\sigma^{2}=\sum_{t, i, r}\left[\varepsilon_{t}^{m}(i, r)\right]^{2} /\left(N_{y} N_{t} N_{i} N_{r}\right)
$$

Furthermore, it may be shown that $\varepsilon_{t}^{\prime \prime}(i, r)=\Omega^{-1 / 2} \varepsilon_{t}(i, r)$ and the loglikelihood function corresponding to equation 7 is:

$$
\begin{gathered}
\log L_{E}=-N_{t} N_{r} N_{i}\left[\log (2 \pi)+\ln \sigma^{2}\right]-N_{r} N_{i} \sum_{t} \ln A_{t}^{2}+\varepsilon_{t}(i, r) \\
N_{r} N_{i}\left[\log \mid\left(R_{M_{-} X}\right)\right] / 2+N_{y} N_{r} N_{i}\left[\log \mid\left(R_{t}\right)\right] / 2-\left\{\left[\varepsilon^{\prime \prime}\right]^{t}\left[\varepsilon^{\prime \prime}\right]\right\} / \sigma^{2}
\end{gathered}
$$

where $\varepsilon^{\prime \prime}$ is the gathering of all stacked $\varepsilon_{t}^{\prime \prime}(i, r)$. The objective function is $-2 \log L_{E}$ and equations 8-11 are imposed as constraints. The only practical difficulty is to set up the term $\left\{\left[\varepsilon^{\prime \prime}\right]^{t}\left[\varepsilon^{\prime \prime}\right]\right\} / \sigma^{2}$. At first glance, it seems that we need to compute 
the square roots of the inverses of $\left[R_{M_{-} X}\right]^{-1 / 2}$ and $\left(R^{t}\right)^{-1 / 2}$. However, only $\left[R_{M_{-} X}\right]^{-1}$ and $\left(R_{t}\right)^{-1}$ are required, since neither constraints: $8-12$, nor the objective function involve either $\left[R_{M_{-} X}\right]^{-1 / 2}$ or $\left(R^{t}\right)^{-1 / 2}$.

A final set of constraints imposed on the estimation procedure relates to the relative magnitudes of Armington elasticities in the upper and lower nests. Recall that the lower nest (with associated elasticity parameter $\sigma_{M}$ ) aggregates imports across sources for a given commodity while the upper nest (with associated elasticity parameter $\sigma_{D}$ ) combines this import composite with domestic goods. Global models commonly assume that $\sigma_{M}=2 \sigma_{D}$. This assumption dates back to the work of Jomini et al.(1991) undertaken in support of the SALTER model of global trade. In their comprehensive review of economic research on trade elasticities, Jomini et.al find that most studies focused on estimating the upper level obstruction elasticity, $\sigma_{d}$, with relatively few estimates of $\sigma_{m}$. For this reason, they sought a "rule of thumb" linking these two parameters. Using earlier estimates of both $\sigma_{D}$ and $\sigma_{m}$ by Corado and de Melo (1983) as a justification, they adopted the "rule of two": $\sigma_{m}=2 * \sigma_{\mathrm{D}}$. In this paper, we first impose this restriction and later test its validity.

\section{Results}

\section{A. Parameter Estimation}

Table 4 displays the estimated results. It is interesting to compare the estimated values to those parameter values associated with the GTAP version 4 global database, which are also presented in Table $4 .{ }^{4}$ Based on this comparison, the

Table 4. Current and estimated trade elasticities

\begin{tabular}{cccccc}
\hline Industry & GTAP & Estimated & Industry & GTAP & Estimated \\
\hline AGR & 2.44 & $1.05^{*}$ & OLT & 2.15 & 2.23 \\
PAG & 2.40 & 3.76 & CHM & 1.90 & 1.98 \\
FMN & 2.41 & 1.08 & MEV & 3.10 & 3.66 \\
CTX & 3.32 & 2.54 & BAM & 3.47 & 2.24 \\
\hline
\end{tabular}

The estimates LS2 are obtained from Table 5.5 of last chapter

*This value is at its lower bound

${ }^{4}$ GTAP elasticity values have been employed by a large number (hundreds) of studies of global trade. In order to obtain a sampling of these studies, go to www.gtap.org and select Resource Center | Applications. 
Table 5. Home preference biases shift parameters (1995=1)

\begin{tabular}{cccccc}
\hline & Developed Countries & \multicolumn{3}{c}{ Less Developed Countries } \\
\hline 1992 & 1989 & 1986 & 1992 & 1989 & 1986 \\
\hline 1.030 & 0.940 & 0.837 & 0.922 & 0.828 & 0.561 \\
\hline
\end{tabular}

GTAP elasticities seem to be too small for processed food (PAG) and motor vehicles and electronic machinery (MEV), and too large for agriculture (AGR), Clothing and Textile products (CTX), Fuels and Minerals (FMN), and Basic Manufacturers (BAM). The GTAP elasticities are quite close to the estimated values for other light manufacturers (OLM), and Chemicals (CHM).

Table 5 displays the estimates of the home bias preference parameter values $\zeta_{t}^{D C}$ and $\zeta_{t}^{L D C}$. This parameter has been scaled to indicate the proportional reduction in import volumes that would occur, at constant prices and incomes, as one moves backward in time from 1995 to 1992, 1989 and 1986. The erosion in home preference biases has been rapid, particularly in LDCs. The most rapid rate of HPB shift seems to occur in the period from 1986 to 1989 for both DC and LDC regions.

Table 6 displays the estimates of the parameters in the covariance matrix $\Omega{ }^{5}$ There is evidence of auto-correlation, heteroscedasticity, and correlation between exports and imports. The error terms are especially highly correlated between 1989 and 1992. Existence of strong correlation between data series tends to discount the information content. In effect, we have less information than would be the case where all observations independent. The high value of heteroscedasticity reflected in the value of $A_{86}$ heavily discounts the 1986 targets in the penalty function, putting instead a larger weight on more recent data. This probably makes good sense, given the difficulty involved in constructing the historical time series.

Table 6. Estimated covariance matrix

\begin{tabular}{c|cccccc}
\hline$\rho$ & $\rho_{89}^{92}$ & $\rho_{86}^{92}$ & $\rho_{86}^{89}$ & $\mathrm{~A}_{92}$ & $\mathrm{~A}_{89}$ & $\mathrm{~A}_{86}$ \\
\hline 0.344 & 0.848 & 0.493 & 0.543 & 1.000 & 1.497 & 2.107 \\
\hline
\end{tabular}

\section{B. Measures of Fit}

As noted above, our approach motivates two sets of descriptive statistics for the

\footnotetext{
${ }^{5} \mathrm{We}$ have conducted an analysis of the residuals to test the assumptions of normality as well as the randomness of $\varepsilon_{t}^{y}$, and the specification on $\Omega$ These results suggest that our econometric model is welldefined.
} 
global CGE model. In this section, we focus on the pseudo R-square statistics to measure the goodness-of-fit for the CGE model. In a simple, linear regression model with a constant term, the $\mathrm{R}^{2}$ value based on least squares estimation is an important measure for evaluating the fit of the regression. The $\mathrm{R}^{2}$ is calculated as 1-SSR/SST where SSR is the sum of squared residuals and SST is the sum of squared deviations of the dependent variable. In this case, the $\mathrm{R}^{2}$ value is interpreted as the proportion of variation explained by the independent variables. If the regression does not contain a constant term, we can obtain an analogous, pseudo- $\mathrm{R}^{2}$ value, without computing the deviations from means (Greene, $\mathrm{p} 155$ ).

The computation of a pseudo- $\mathrm{R}^{2}$ in our case is similar to that for a regression model without constant term. Consider the model defined in equation 4.6 We define SSR and SST as:

$$
\begin{aligned}
\mathrm{SSR} & =\sum_{i, r}\left[\varepsilon_{t}^{y}(i, r)\right]^{2} \\
\mathrm{SST} & =\sum_{i, r}\left[\log \left(S_{t}^{y}(i, r) / S_{95}^{y}(i, r)\right)\right]^{2}
\end{aligned}
$$

This definition has some meaningful implications in the CGE context. As we know, the $\mathrm{R}^{2}$ measures are initially intended to evaluate the contribution of independent variables in a linear regression model to reducing the variation of the dependent variable, measured as SST. In a simple linear regression model with constant term $y_{j}=\alpha+\beta x_{j}, \operatorname{SST}=\sum\left[y_{j}-\bar{y}\right]^{2}$. The term $\bar{y}$ reflects a naïve guess for the value of $y_{j}$ in the absence of the model; and SST is the sum of squared deviations of the dependent variable from this naïve guess. Analogously, we may define in CGE context:

$$
\mathrm{SST}=\sum_{i, r}\left[\log \left(S_{t}^{y}(i, r) / S_{95}^{y}(i, r)\right)-\log \left(\dot{S}_{t}(i, r) / S_{95}^{y}(i, r)\right)\right]^{2}
$$

where, $\dot{S}_{t}(i, r)$ denotes the best guess without the CGE model. Arguably, the best naïve guess is to assume the share structure at time $t$ remains the same as the benchmarked share structure, or $\dot{S}_{t}(i, r)=S_{95}^{y}(i, r)$. Therefore, $\log \left(\dot{S}_{t}(i, r) / S_{95}^{y}(i, r)\right)$ $=0$ and we have equation 14 .

Table 8 displays the Analysis of Variance (ANOVA) table for our model. We find that our model explains about $30-65 \%$ of total variation. It is no surprise that

${ }^{6}$ Please note that R-Square values will change if we use another model (e.g. equation 3). 
Table 7. Analysis of Variance*

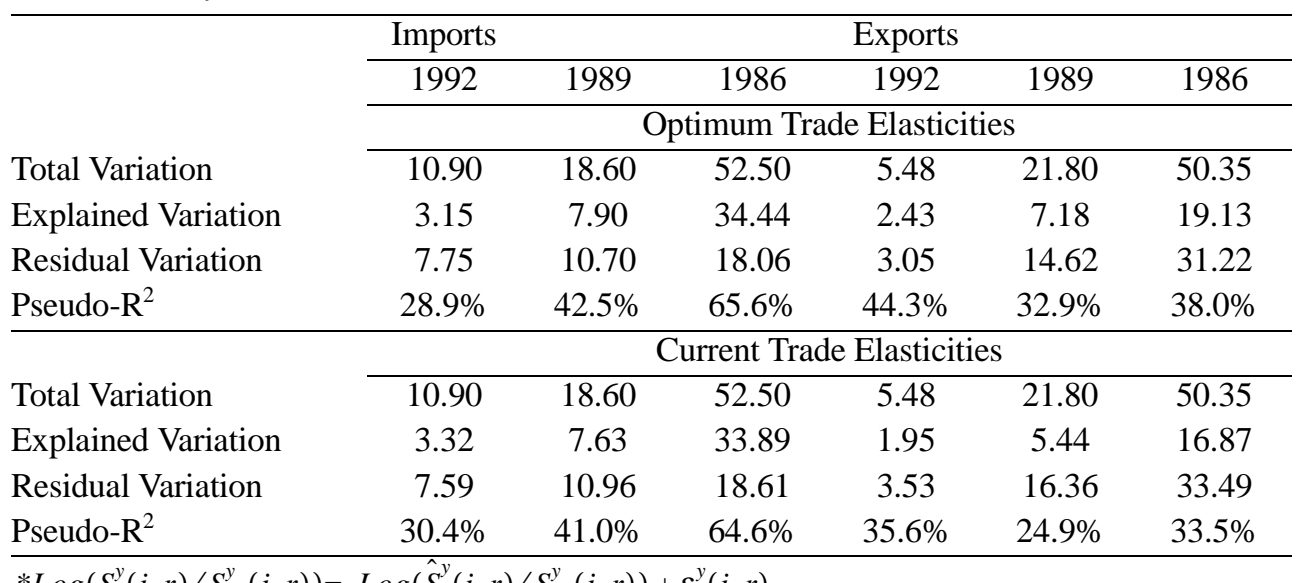

${ }^{*} \log \left(S_{t}^{y}(i, r) / S_{95}^{y}(i, r)\right)=\log \left(\hat{S}_{t}^{y}(i, r) / S_{95}^{y}(i, r)\right)+\varepsilon_{t}^{y}(i, r)$

these R-squares are relatively low. This is due to the nature of this study where cross sections of individual data are analyzed and the model is a dramatic simplification of reality. We also note that the $R^{2}$ values for imports in 1992 and 1989 are lower than that for the year 1986 while the reverse is the case with respect to exports. Table 7 also presents results using the standard GTAP elasticity values. Calculation of the optimal elasticities primarily improves the fit of the model with respect to exports. Measures of fit with respect to imports change only marginally.

\section{Hypothesis Tests}

The second use of the descriptive statistics generated by our approach to estimation is hypothesis testing based on the likelihood ratio test using equation 7 . The first test we consider involves exploring whether the optimum estimates of trade parameters $\hat{\sigma}^{k}$, significantly improve the model's performance with the current GTAP elasticities, $\sigma_{0}^{k}$. The null hypothesis is: $\mathrm{H}_{0}: \sigma^{k}=\sigma_{0}^{k}$. Table 8 displays the results of the test. The first two columns show the values of the loglikelihood, first unrestricted and then with the restrictions associated with the null hypothesis. The third column constructs the log-ratio statistic. ${ }^{7}$ The fourth column shows the probability of the null hypothesis given the statistic in column three. Accordingly, we reject the null hypothesis. Therefore, the current GTAP

${ }^{7}$ In light of the fact that one of the estimated parameters reaches the lower bound in the unrestricted model (Table 4), hypothesis test is actually a conservative one, cince the log-likelihood ratio without boundary restriction would be larger. 
Table 8. Results of first hypothesis: GTAP Parameters Imposed

\begin{tabular}{cccc}
\hline \multicolumn{4}{c}{ Log-Ratio Metric } \\
\hline $2 \log \left(\hat{L}_{U}\right)$ & $2 \log \left(\hat{L}_{R}\right)$ & $\mathrm{C}=-2 \log \left(\hat{L}_{R} / \hat{L}_{u}\right)$ & $\mathrm{P}\left(\lambda_{8}^{2} \geq c\right)$ \\
-175.8 & -202.9 & 27.1 & 0.005 \\
\hline
\end{tabular}

Table 9. Results of second hypothesis: Rule of two

\begin{tabular}{ccccc}
\hline \multicolumn{5}{c}{ Log-Ratio Metric } \\
\hline $2 \log \left(\hat{L}_{U}\right)$ & $2 \log \left(\hat{L}_{R}\right)$ & $\mathrm{C}=-2 \log \left(\hat{L}_{R} / \hat{L}_{u}\right)$ & $\mathrm{P}\left(\lambda_{8}^{2} \geq c\right)$ & $\omega$ \\
-173.8 & -175.8 & 2 & 0.158 & 2.69 \\
\hline
\end{tabular}

elasticities are associated with a significantly poorer fit of the historical trade shares, compared with the estimated elasticities.

In the second hypothesis test, we examine the relationship $\sigma_{M}=2 \sigma_{D}$ : the socalled "rule of two." So far, this has been a maintained hypothesis. To test the restriction, we let $\sigma_{M}=\omega \sigma_{D}$ in the unrestricted model. The restricted model is the formerly unrestricted model shown in the first column of Table 8 . The null hypothesis is $\mathrm{H}_{0}$ : $\omega=2$, and the probability of this null hypothesis, given the $\log$ ratio statistic in column three is 0.158 . Accordingly, the null hypothesis is not rejected.

\section{Conclusions and Future Directions for Research}

Global CGE models are widely used for economic research and analysis of trade policy questions. However, these models are widely criticized for resting on weak empirical foundations. Specifically, key parameters are often gleaned from unrelated economic studies, and CGE modelers rarely validate their models against the historical record. In response to this deficiency, the present paper develops an econometrically based approach to parameter estimation for a variant of the widely used GTAP model of global trade. This approach builds on an approximate likelihood function inspired by the recent literature or dynamic, macro-econometrics. The set of optimum trade elasticities is obtained by maximizing this likelihood function in the context of a model backcasting exercise over the period 1995 to 1986.

The approximate likelihood function also permits us to develop a formal framework for hypothesis testing which is used to test two null hypotheses about the trade elasticities in our model. The first of these is the hypothesis that the true 
elasticities are equal to the trade elasticities currently in the GTAP parameter file. This is rejected. We find that the two sets of elasticities differ most for primary agriculture and fuels and mineral products (GTAP values are too large), whereas the GTAP estimates for processed food products, motor vehicles and electrical machinery are too small.

The second null hypothesis tested is the widely employed "rule of two", whereby the elasticity of substitution among imports from different sources for a given product is set equal to twice the value of the domestic-import substitution elasticity. We fail to reject this hypothesis, thereby lending additional credence to this rule of thumb.

Finally, we develop a goodness of fit measure, which is analogous to the pseudo- $\mathrm{R}^{2}$ used in regression analysis. This permits us to assess how well the fitted model predicts historical behavior, comparing the "goodness-of-fit" of alternative model specifications within the same broad econometric model. An interesting extension of this measure would be to use it to evaluate the individual contributions of the different exogenous shocks (e.g., tariff reductions, endowment shocks, etc.) in a manner analogous to factor decomposition analyses in regression models.

In summary, we believe that there is much to be gained by following the lead of the dynamic macro-ecometricians in nesting CGE models within an econometric framework that admits errors due to model specification and measurement problems. While such efforts are extremely time-consuming - not least due to the challenge of obtaining historical time series for the model shocks and targets -they also promise to bear considerable fruit. It is only by predicting the past that CGE models will garner credibility for analysis of the future.

Received 8 May 2002, Accepted 10 August 2003

\section{References}

Albrego, L. and J. Whalley. (2002) "Decompositional Analysis Using Numerical Equilibrium Models: Illustrations from the Trade Literature", paper presented at the conference on Frontiers in Applied General Equilibrium Modeling, Yale University, April 5-6.

Altug, S. (1989). Time to Build and Aggregate Fluctuations: Some New Evidence. International Economic Review 30: 889-921.

Arndt, C., T. W. Hertel, B. Dimaranan, K. Huff, and R. McDougall, (December 1997). 
"China in 2005: Implications for the Rest of the World." Journal of Economic Integration. 5: 505-547.

Arndt, C., S. Robinson, and F. Tarp (Forthcoming). Parameter Estimation for a Computable General Equilibrium Model: A Maximum Entropy Approach. Economic Modelling.

Brooke, A., D. Kendrick and A. Meeraus (1992). GAMS: A Users Guide, Release 2.25, Danvers, Massachusetts: Boyd and Fraser Publishing Company.

Corado, C. and J. de Melo (1983). An ex-ante model for estimating the impact on trade flows of a country's accession to a customs union. Discussion Paper No. DRD67, World Bank, Washington, DC.

Coyle, W., M. Gehlhar, T.W. Hertel, Z. Wang, and W. Yu, (1998). Understanding the Determinants of Structural Change in World Food Markets. American Journal of Agricultural Economics, 80(5): 1051-1061.

Dawkins, C., T.N. Srinivasan, J. Whalley (2000). Calibration. In E.C. Learner and J. Heckman, Handbook of Econometrics, North-Holland Press.

Gallant, R. and A. Holly (1980). Statistical Inference in an Implicit, Nonlinear, Simultaneous Equation Model in the Context of Maximum Likelihood Estimation. Econometrica 48: 697-720.

Gehlhar, M. J. (1994). Economic Growth and Trade in the Pacific Rim: An Analysis of Trade Patterns. Unpublished PhD dissertation, Purdue University, Department of Agricultural Economics.

Gehlhar, M. J. (1998). Time-Series Data of Merchandise Trade. The GTAP 4 Data Base, Chapter 7. Center for Global Trade Analysis, Purdue University.

Greene, W.H. (1993). Econometric Analysis, Second Edition, Englewood Cliffs, New Jersey: Prentice Hall.

Hansen, L., and J. Heckman (1996). The Empirical Foundations of Calibration. Journal of Economic Perspectives 10(1): 87-104.

Hertel, T. (1997). Global Trade Analysis: Modeling and Application, Cambridge University Press.

Hoover, K. (1995). Fact and Artifacts: Calibration and the Empirical Assessment of RealBusiness-Cycle Models. Oxford Economic Papers 47: 24-44.

Ianchovichina, E., and W. Martin (2001). Trade Liberalization in china's Accession to WTO. Journal of Economic Integration 16(4): 421-445.

Johnson, R. and D. Wichern (1982). Applied Multivariate Statistical Analysis. PrenticeHall, Inc., Englewood Cliffs, New Jersey.

Jomini, P., J. F. Zeitsch, R. McDougall, A. Welsch, S. Brown, J. Hambley, and J. Kelly (1991) SALTER: A General Equilibrium Model of the World Economy 1. Model Structure, Database and Parameters. Canberra, Australia: Industry Commission.

Jorgenson, D. (1984). Econometric Methods for Applied General Equilibrium Analysis. Scarf, Herbert E. and Shoven, John B. (eds.) Applied General Equilibrium Analysis. New York, Cambridge University Press.

Jomini, P., J. F. Zeitsch, R. McDougall, A. Welsh, S. Brown, J. Hambley, and J.Kelly 
(1991). SALTER: A General Equilibrium Model of the World Economy 1. Model Structure, Database and Parameters. Canberra, Australia: Industry Commission.

Kehoe, T.J., C. Polo, and F. Sancho (1995). An Evaluation of the Performance of an Applied General Equilibrium Model of the Spanish Economy. Economic Theory 6: 115-141.

Kehoe, P and T. Kehoe (1994). A Primer on Static Applied General Equilibrium Models. Quarterly Review, Federal Reserve Bank of Minneapolis: 2-16.

Kydland F. and E. Prescott (1982). Time to Build and Aggregate Fluctuations. Econometrica 50: 1345-70.

Liu, J. Parameter Estimation and Measures of Fit in a Global, General Equilibrium Model. Ph.D. dissertation, Department of Agricultural Economics, Purdue University. W. Lafayette, IN.

McCallum, J.T. (1995). "Natural Borders Matter: Canada-U.S. Regional Trade Patterns." American Economic Review 85: 615-623

McDougall, R. A., A. Elbehri, and T.P. Truong eds. (1998). Global Trade, Assistance, and Protection: The GTAP 4 Data Base. Center for Global Trade Analysis, Purdue University.

McKibbin, W. J. and P.J. Wilcoxen (1999). The Theoretical and Empirical Structure of the G-Cubed Model. Economic Modeling 16: 123-148.

McKitrick, Ross R. (1998). The Econometric Critique of Computable General Equilibrium Modeling: The Role of Parameter Estimation. Economic Modeling 15: 543-573.

Roberts, Barbara M. (1994). Calibration Procedure and the Robustness of CGE Models: Simulations With A Model for Poland. Economics of Planning 27: 189-120.

Rutherford, Thomas F. (1998). GTAP4: A GAMS Implementation. http://debrea.Colorado.edu/ gtap/gtapingams.html.

Sims, C. (1980). Macroeconomics and Reality. Econometrica 48: 1-48.

Sims, C. (1996). Macroeconomics and Methodology. Journal of Economic Perspectives 10: $105-120$.

Singleton, K. (1988). Econometric Issues in the Analysis of Equilibrium Business Cycle Models. Journal of Monetary Economics 21: 361-86.

Wang, Z. (1999). Time Series National Account Data Aggregated at GTAP Version 4 Level. Unpublished data.

Watson, M.W. (1993): "Measures of Fit for Calibrated Models. Journal of Political Economy. 101: 1011-1041. 